\title{
OTOTOXICIDADE EM TRABALHADORES POR EXPOSIÇÃO A AGROTÓXICOS
}

\author{
Meire Aparecida Judai ${ }^{1}$ \\ Patricia Alexandra Antunes ${ }^{2}$
}

Resumo: O Brasil alcançou em 2009 o primeiro lugar no ranking mundial de consumo de agrotóxicos, embora não seja o principal produtor agrícola mundial. Algumas publicações relatam que no Brasil trabalhadores expostos a agrotóxicos, apresentam alta incidência de neuropatias periféricas e também a presença de perdas auditivas do tipo neurossensorial de grau leve a moderado. Com apenas dias de exposição, pode-se apresentar perda auditiva, variando o grau de leve a profunda. Diante do exposto, concluise que é necessário analisar o perfil audiométrico de moradores e trabalhadores agrícolas, realizar pesquisas, principalmente na região do Pontal do Paranapanema, avaliando a influência dos agrotóxicos sobre a audição, propiciando discussões sobre a necessidade de programas preventivos destinados a essa população.

Palavras-chave: Ototoxicidade, Saúde Ambiental, Saúde Auditiva

\footnotetext{
${ }^{1}$ Mestranda em Meio Ambiente e Desenvolvimento Regional, UNOESTE. meirejudai@unoeste.br.

2 Doutora em Química Analítica - USP - São Carlos. Prof. Dra. UNOESTE. antunes@unoeste.br.
} 


\section{INTRODUÇÃO}

No Brasil, há mais de mil produtos comerciais de agrotóxicos diferentes, que são elaborados a partir de 450 ingredientes ativos, aproximadamente. O Ceará apareceu no Censo Agropecuário do Instituto Brasileiro de Geografia e Estatística (IBGE) de 2006 como o quarto estado brasileiro em número de estabelecimentos que utilizam agrotóxicos, o que é diferente de ser o quarto que mais consome. Não temos dados muito precisos porque a obrigação do controle, do fluxo de agrotóxicos em cada estado, de acordo com a lei federal, cabe ao órgão estadual de meio ambiente e de agricultura. (RIGOTTO, 2011)

Estudos revelam que os agrotóxicos provocam danos ao meio ambiente, ecossistema e a saúde humana. Várias doenças evidenciam o quadro alarmante com relação á utilização desmedida e precariamente controlada dos agrotóxicos. Entre elas estão os problemas pulmonares, dérmicos, cânceres, alterações visuais e auditivas, entre outros. A audição de moradores dos entornos e trabalhadores que estão expostos aos agrotóxicos, sejam na manipulação e preparação ou na aplicação, pode sofrer grandes prejuízos, uma vez que vários estudos demonstram os estragos produzidos pelos mesmos.

Algumas publicações relatam que no Brasil trabalhadores expostos a agrotóxicos do tipo organofosforado, apresentam alta incidência de neuropatias periféricas e também a presença de perdas auditivas do tipo neurossensorial de grau leve a moderado. (KÖRBES et al, 2010) Com apenas dias de exposição, pode-se apresentar perda auditiva, variando o grau de leve a profunda. (HOSHINO et al, 2008)Em pesquisas mais recentes, através de um grupo de trabalhadores expostos a inseticidas do tipo organofosforado e piretróide, foram constatadas que as exposições crônicas a estes inseticidas afetam o sistema auditivo nos níveis periférico e central. (MANJABOSCO, MORATA e MARQUES, 2004)

Porém não é conhecida nenhuma pesquisa na região do Pontal do Paranapanema, voltada à questão da audição do trabalhador exposto ao agrotóxico, exposição essa que pode desencadear um prejuízo irreversível, se detectado tardiamente. Os dados até o momento coletados e as notificações efetivadas pelo Centro de Referência em Saúde do Trabalhador - Regional de Presidente Prudente, por intermédio do SINAN (Sistema de Informação de Agravos de Notificação) evidencia apenas as Perdas Auditivas Induzidas pelo Ruído.

\section{A UTILIZAÇÃO DOS AGROTÓXICOS NO BRASIL}


A Legislação ambiental brasileira tem sido considerada uma das mais completas de todo o mundo, o que não tem garantido, entretanto, seu devido cumprimento, tampouco que os principais setores produtivos, principalmente no que diz respeito aos aspectos sociais e ambientais, se aproxime da sustentabilidade. Nas últimas décadas a concepção e implementação de políticas ambientais se restringiam a um conjunto de medidas com perfil setorial, raramente articuladas às ações de desenvolvimento regional e urbano, e voltadas principalmente para o controle de índices excessivos de poluição, para a gestão da qualidade do ar, das águas, dos níveis de ruído, e para a criação de áreas de preservação.

Da mesma forma, houve um aumento anual do consumo do agrotóxico, influenciando no contexto do desenvolvimento regional e piora da qualidade do ar, água entre outros, prejudicando assim o meio ambiente. O Brasil alcançou em 2009 o primeiro lugar no ranking mundial de consumo de agrotóxicos, embora não seja o principal produtor agrícola mundial. A maior parte dos agrotóxicos utilizados acaba atingindo o solo e as águas principalmente pela deriva na aplicação, controle de ervas daninhas, lavagem das folhas tratadas, lixiviação, erosão, aplicação direta em águas para controles de vetores de doenças, resíduos de embalagens vazias, lavagens de equipamentos de aplicação e efluentes de indústrias de agrotóxicos. (AUGUSTO et. al., 2012)

\begin{abstract}
Segundo Londres (2011), foi na ultima década que o uso de agrotóxicos no Brasil assumiu as proporções mais assustadoras. Entre 2001 e 2008 a venda de venenos agrícolas no pais saltou de pouco mais de US\$ 2 bilhões para mais US\$ 7 bilhões, quando alcançamos a posição de maior consumidor mundial de venenos. Foram 986,5 mil toneladas de agrotóxicos aplicados. Em 2009 ampliamos ainda mais o consumo e ultrapassamos a marca de 1 milhão de toneladas - o que representa nada menos que $5,2 \mathrm{~kg}$ de veneno por habitante. Os dados são do Sindag (Sindicato Nacional da Industria de Produtos para Defesa Agrícola). Devido à repercussão negativa que o aumento do uso de venenos começou a causar nos meios de comunicação, a organização não divulgou o volume de agrotóxicos comercializado em 2010, mas apenas o faturamento do setor: US\$ 7,2 bilhões.
\end{abstract}

Existem atualmente 366 ingredientes ativos registrados no Brasil para uso agrícola, pertencentes a mais de 200 grupos químicos diferentes, que dão origem a 1.458 produtos formulados para venda no mercado. São inseticidas, fungicidas, herbicidas, nematicidas, acaricidas, rodenticidas, moluscidas, formicidas, reguladores e inibidores de crescimento. Os herbicidas sozinhos representam $48 \%$ deste mercado, seguidos pelos inseticidas (25\%) e pelos fungicidas (22\%). (PELAEZ et al, 2009 citado por LONDRES, 2011)

Pesticidas do grupo dos organofosforados, compostos anticolinesterásicos que causam variado grau de toxicidade para o ser humano, são amplamente utilizados na agricultura há muitas décadas. Em razão do benefício do agrotóxico para o 
sucesso do plantio, o trabalhador tem a tendência de superestimar seus efeitos benéficos para o plantio, desconsiderando os malefícios à saúde em curto, médio e longo prazo. Embora um grande número de pesticidas tenha sido descoberto no início do século, seus efeitos deletérios foram relatados somente a partir de 1932. (KÖRBES et al, 2010)

\section{TOXICIDADE DOS AGROTÓXICOS - EFEITOS PARA A SAÚDE}

Não há registros oficiais sobre os efeitos crônicos causados pelo contato com os agrotóxicos, o que concorre para a livre utilização por parte das empresas agroquímicas. O número de mortes por agrotóxico - notificadas - chega a mais de uma centena nos três estados da região Sul; também a mais de uma centena em São Paulo e Espírito Santo, na região Sudeste; o mesmo na Bahia e Goiás, respectivamente nas regiões Nordeste e Centro Oeste e, finalmente, chega à casa de mais de duas centenas de mortes nos estados do Ceará e de Pernambuco. Cerca de 170 mortes por ano causadas pelo uso de agrotóxicos. (BOMBARDI, 2011)

As pessoas mais expostas aos perigos da contaminação pelos agrotóxicos são aquelas que têm contato com eles no campo. Há os aplicadores, preparadores de caldas e responsáveis por depósitos, que têm contato direto com os produtos, e há também os trabalhadores que têm contato indireto com os venenos ao realizar capinas, roçadas, colheitas etc. Este segundo grupo é, na verdade, o de maior risco, uma vez que o intervalo de reentrada nas lavouras não costuma ser respeitado e estes trabalhadores não usam proteção. (LONDRES, 2011)

\section{TRABALHADORES EXPOSTOS AOS AGROTÓXICOS}

Segundo Londres (2011), no período de 1999 a 2009, foram notificados pelo SINITOX (Sistema Nacional de Informações Tóxico-Farmacológicas - Ministério da Saúde/FIOCRUZ), cerca de 62 mil intoxicações por agrotóxicos de uso agrícola. Isto significa que foram aproximadamente 5.600 intoxicações por ano no país, o que equivale a uma média de 15,5 intoxicações diárias, ou uma a cada 90 minutos. Entretanto, por mais grave que aparente, a realidade é que eles estão muito aquém de representar o número real das intoxicações por agrotóxico de uso agrícola.

O Sinitox tem a função de orientar as famílias, os agentes de saúde na forma de lidar com intoxicações. Já o Sistema de Informação de Agravos de Notificação (SINAN) é vinculado diretamente ao Ministério da Saúde, com o objetivo de coletar os dados de 
referentes á agravos à saúde do trabalhador, dentre eles as intoxicações exógenas, as quais a intoxicação por agrotóxico está vinculada. Porém os dados são diferentes, não há como cruzá-los. Há números discrepantes, às vezes tem o dobro de intoxicações no Sinitox para o mesmo ano medido pelo SINAN.

A partir de 2005 a notificação passou a ser compulsória. Em janeiro deste ano a notificação de intoxicação por agrotóxicos passou a ser obrigatória, por intermédio do Sinan. Os profissionais de saúde, por sua vez, enfrentam no Brasil uma enorme dificuldade para diagnosticar, registrar e até mesmo encaminhar pacientes intoxicados por agrotóxicos. Sabe-se que o número de registros é muito menor do que o número real de intoxicações - a própria Organização Mundial da Saúde reconhece que, para cada caso registrado de intoxicação pelos agrotóxicos, há 50 não notificados. (LONDRES, 2011)

É possível afirmar que as doenças relacionadas ao trabalho encontram-se na invisibilidade social devido á sua subnotificação. Ainda que a partir do NTEP, houve um aumento dos registros.

Os trabalhadores atingidos pelos agrotóxicos são desde o camponês pequeno proprietário até um trabalhador contratado por empresas. Desde um piloto de avião que vai pulverizar agrotóxicos até um pequeno produtor, todos estão expostos aos agrotóxicos. E há uma questão nisso: eles conhecem pouco os procedimentos para se proteger. (BOMBARDI, 2011)

Além disso, é importante destacar que os perigos da intoxicação crônica, aquela que mata devagar, com o desenvolvimento de doenças neurológicas, hepáticas, respiratórias, renais, cânceres etc., ou que provoca o nascimento de crianças com malformações genéticas, não advêm apenas do contato direto com venenos. (Londres, 2011)

Segundo Londres (2011) existem 3 tipos de intoxicação:

- Intoxicação aguda, cujos sintomas surgem rapidamente, algumas horas após a exposição ao agrotóxico. Os efeitos podem incluir dores de cabeça, náuseas, vômitos, dificuldades respiratórias, fraqueza, salivação, cólicas abdominais, tremores, confusão mental, convulsões, entre outros. Pode ocorrer de forma leve, moderada ou grave, dependendo da quantidade absorvida. Em muitos casos pode levar à morte.

- Intoxicação subaguda ou sobreaguda, ocorre por exposição moderada ou pequena a produtos alta ou medianamente tóxicos. Os efeitos podem aparecer em alguns dias ou semanas, podem incluir dores de cabeça, fraqueza, mal-estar, dor de estômago, sonolência, entre outros.

- Intoxicação crônica que caracteriza-se pelo surgimento tardio. Aparece após meses ou anos da exposição leve ou moderada a um ou vários produtos tóxicos. Os sintomas são normalmente subjetivos e podem incluir perda de peso, fraqueza muscular, depressão, irritabilidade, insônia, anemia, dermatites, alterações hormonais, problemas imunológicos, efeitos na reprodução (infertilidade, malformações congênitas, abortos), doenças do fígado e dos rins, doenças respiratórias, efeitos no desenvolvimento da criança, entre outros. Normalmente o 
diagnóstico da intoxicação crônica é difícil de ser estabelecido. Os danos muitas vezes são irreversíveis, incluindo paralisias e vários tipos de câncer.

Segundo Finkler (2012), ocorre uma ação dos agrotóxicos sobre o sistema nervoso causando sintomas tardios, o que significa que eles não ocorrem imediatamente após a intoxicação aguda. Em doses baixas e repetidas, os organofosforados, possivelmente, induzem a perda ou redução dos ramos neuronais. O trabalhador agrícola está exposto a vários agentes nocivos à saúde, incluindo produtos químicos específicos, como agrotóxicos.

\section{OTOTOXICIDADE}

Estudos revelam os agrotóxicos como causa de vários danos à saúde, dentre eles as perdas auditivas. Voltam-se com maior ênfase as perdas auditivas de trabalhadores por exposição a ruído, apresentados pela literatura com inúmeros estudos.

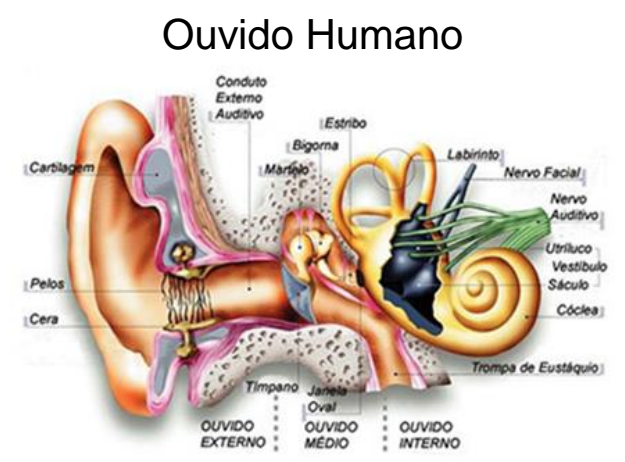

Fonte da figura: http://www.explicatorium.com/CFQ8/Som_Ouvido_humano.php

Porém, outros fatores de risco para a saúde auditiva têm sido observados com frequência nos ambientes de trabalho, como a exposição a produtos químicos de efeito ototóxico.

A ototoxicidade deve ser considerada e estudada como um problema de saúde pública. Existem mais de 200 substâncias que já foram citadas na literatura como ototóxicas, sendo a maioria delas não identificadas como nocivas ao homem. (HOSHINO et al, 2008) 


\title{
som Fórum Ambiental
}

da Alta Paulista

ISSN 1980-0827

Volume 9, Número 11, 2013

Saúde, Saneamento e Meio Ambiente

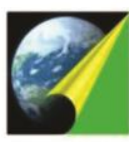

ANAP

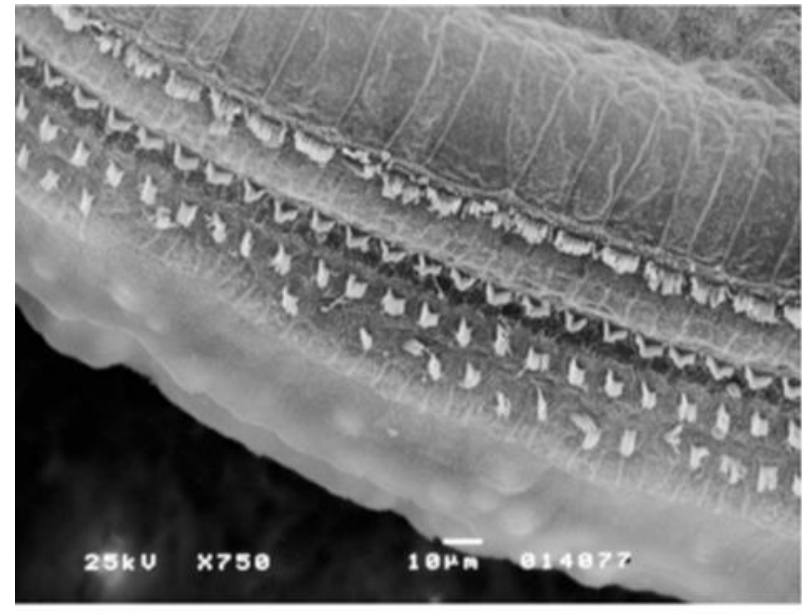

Figura 1. Aspectos morfológicos da cóclea de uma cobaia intoxicada pelo organofosforado, evidenciando lesão de estereocilios de CCE Fonte: ilustração cedida pela autora( ${ }^{(35)}$

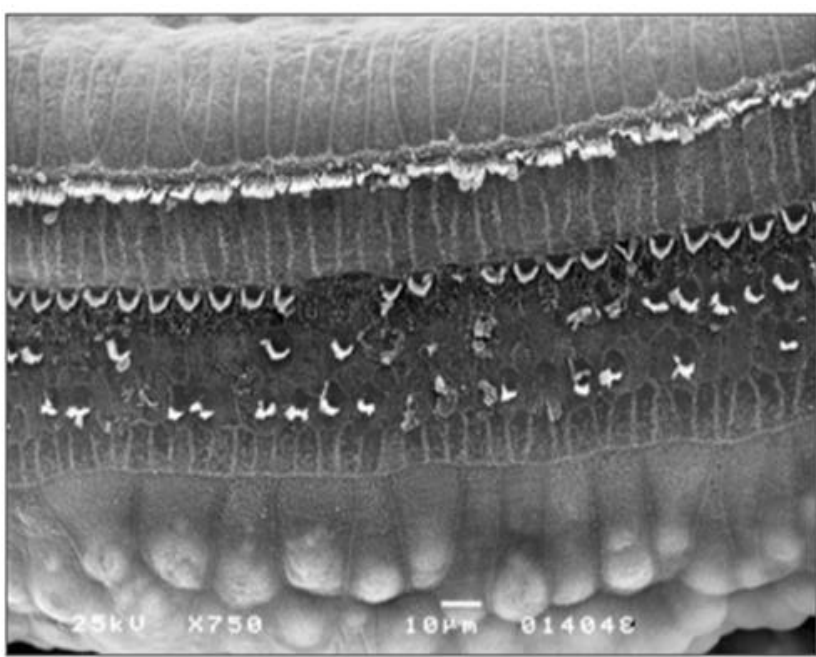

Figura 4. Fotomicrografia de órgão de Corti de cobaia do grupo 3 , evidenciando a E3. Aumento de 750 vezes.

\section{Fonte: KÖRBES, D; SILVEIRA, A. F ; HYPPOLITO , M. A.; MUNARO G., 2010}

Os produtos neurotóxicos podem causar problemas sérios, inclusive a perda de audição. Este dado é muito importante, pois há evidências de que a perda auditiva possa ser uma manifestação precoce de intoxicação. Além disso, o produto neurotóxico pode lesar não somente o componente periférico da audição, mas também o componente central. Por isso, são necessárias novas pesquisas para conhecer melhor os efeitos associados do ruído e dos produtos químicos sobre a audição, priorizando padronizações de maior segurança. Compreender melhor os efeitos das exposições combinadas pode auxiliar no desenvolvimento de estratégias de prevenção mais efetivas em relação à perda auditiva. São poucos os estudos que relatam a associação entre exposição a agrotóxicos e alterações auditivas, mas todos concordam com esta associação.

\begin{abstract}
No sistema vestibulococlear, o efeito de agentes ototóxicos pode manifestar-se em lesões de células ciliadas externas (CCE), lesões do VIII par craniano, alterações no sistema vestibular e alterações no sistema nervoso central (SNC). A ação neurotóxica de algumas substâncias químicas encontradas nos ambientes de trabalho pode afetar não somente a audição e o equilíbrio, mas também o tronco cerebral e via auditivas centrais. Há evidências de que a alteração auditiva possa ser uma manifestação precoce de intoxicação por organofosforados. (KÖRBS et. al., 2010)
\end{abstract}

\section{CONCLUSÃO}

Diante do exposto, conclui-se que é necessário analisar o perfil audiométrico de moradores e trabalhadores agrícolas, realizar pesquisas, principalmente na região do Pontal do Paranapanema, na qual a utilização é significativa, avaliando a influência dos agrotóxicos sobre a audição, propiciando discussões sobre a necessidade de programas preventivos destinados a essa população. 
Uma vez que estudos comprovam o prejuízo da saúde auditiva por exposição aos agrotóxicos, seja direta ou indiretamente, acometendo trabalhadores e moradores dos entornos das áreas mais afetadas pela aplicação, é de fundamental relevância compreender a situação das intoxicações por exposição aos agrotóxicos, mais especificamente das ototoxicidades, na região do Pontal do Paranapanema, bem como obter subsídios para uma possível modificação do Protocolo de Complexidade Diferenciada 5 - Perda Auditiva Induzida pelo Ruído - PAIR (Brasília, 2006) que beneficia apenas trabalhadores expostos ao ruído em detrimento de trabalhadores expostos á produtos químicos ou altas temperaturas.

\section{REFERÊNCIAS}

AUGUSTO, L. G. C. et al. Dossiê ABRASCO - Um alerta sobre os impactos dos agrotóxicos na saúde. ABRASCO, Rio de Janeiro, junho de 2012. 2ª Parte. 135p.

BOMBARDI, L. M. Agrotóxico é nova faceta da violência no campo. 2011. Extraido do Jornal Brasil de Fato. Disponível em http://estadocapitaltrabalho.wordpress.com/2012/05/09/agrotoxico-e-nova-faceta-daviolencia-n... 29/09/2012 Acesso em 25/10/2012.

BOMBARDI, L. M. Intoxicação e morte por agrotóxicos no Brasil: a nova versão do capitalismo oligopolizado. 2011. Departamento de Geografia - USP, São Paulo.

BRASIL, Ministério da Saúde, Secretaria de Atenção à Saúde - Departamento de Ações Programáticas Estratégicas - Área Técnica de Saúde do Trabalhador. Protocolo de Complexidade Diferenciada 5. Série A. Normas e Manuais Técnicos, 1. ${ }^{a}$ edição - 2006.

FINKLER, A. D. et al. Otoprotection in guinea pigs exposed to pesticides and ginkgo biloba. Braz J Otorhinolaryngol., 2012.

GUIMARÃES, Paulo Ricardo Bittencourt. Métodos Quantitativos Estatísticos. Curitiba: IESDE Brasil S.A., 2008.

HOSHINO, A. C. H. et al. Estudo da ototoxicidade em trabalhadores expostos a organofosforados. Revista Brasileira de Otorrinolaringologia, 2008.

INSTITUTO BRASILEIRO DE GEOGRAFIA E ESTATÍSTICA (IBGE), http://www.ibge.gov.br/cidadesat/xtras/uf.php?coduf=35, 2010. Acesso em 02/06/2013.

KÖRBS, D. et al. Alterações no sistema vestibulococlear decorrentes da exposição ao agrotóxico: revisão de literatura. Revista Sociedade Brasileira de Fonoaudiologia, 2010. 
KÖRBS, D. et al. Ototoxicidade por organofosforados: descrição dos aspectos ultraestruturais do sistema vestibulococlear de cobaias. Brazilian Journal of Otorhinolaryngology 76 (2) Março/Abril 2010.

LONDRES, Flavia. Agrotóxicos no Brasil: um guia para ação em defesa da vida. - Rio de Janeiro: AS-PTA - Assessoria e Serviços a Projetos em Agricultura Alternativa, 2011.

MANJABOsco, C. W. , MORATA, T. C. e MARQUES, J. M. Perfil Audiométrico de Trabalhadores Agrícolas. Seção: Original Article, 2004. Vol 8, Num. 4.

RIGOTTO, R. - Entrevista - por Gustavo Colares - Ciência engajada, 17 de Agosto de 2011. 